\title{
MULTI MEDIA UNTUK MENUNJANG EDUKASI UPAYA PENGURANGAN RESIKO BENCANA DI KAWASAN GEOPARK CILETUH
}

\author{
Multi Media to Support Disaster Risk Reduction Education \\ in Ciletuh Geopark Area
}

\author{
Diah Natarina ${ }^{1)}$ dan Agus Sachari ${ }^{2)}$ \\ 1) 2) Fakultas Seni Rupa dan Desain, Institut Teknologi Bandung \\ Jalan Ganesha 10, Bandung 40132 \\ E-mail: diah.natarina@students.itb.ac.id
}

\begin{abstract}
Government revenue from the Tourism Sector is primary state income. The geological phenomenon when the ocean floor that roses to the surface of the sea and becomes Indonesian Archipelago was the result of evolutionary process millions of years ago. Currently, the earth has reached its maturity, however on the other hand, humans and their civilizations continuously developing. In the beginning, humans respected nature but the development of civilization and science then changed humans and the natural system causing natural disasters frequently occurred. Ciletuh in West Java, as a part of the conservation area of UNESCO Global Geoparks has become an alternative geotourism destination. This place has undergone an adjustment in its natural system due to the development of four-wheeled transportation access is facing the potential problem of landslides. This research aims to reduce the risk of landslides through a range information system. In achieving the objectives, qualitative methodology used is descriptive-analytical. Data collection techniques by conducting a literature review, observation and in-depth interviews. Results showed that sources, while on the surface it is widely spread needs to be equipped with multimedia applications. Through a visual communication design approach, graphic information as educational media of disaster risk reduction makes it easier for public to understand. Ciletuh which has become a UNESCO Global Geopark Network area must have complete regulations as a reference in managing disaster resilience on the geotourism zone.
\end{abstract}

Keywords: Ciletuh, education, landslides, geotourism, multimedia, signage

\begin{abstract}
Abstrak
Pemasukan Negara dari Sektor Pariwisata menjadi sumber pemasukan andalan. Peristiwa geologis dasar samudra yang terangkat kepermukaan laut menjadi Nusantara adalah hasil proses evolusi berjuta-juta tahun lalu. Saat ini, di satu sisi bumi sudah mencapai titik kematangannya. Akan tetapi, di sisi lain makhluk hidup dan peradabannya terus berkembang. Pada awalnya manusia sangat memuliakan alam namun peradaban dan perkembangan ilmu pengetahuan kemudian mengubah manusia dan tata alam sehingga bencana alam sering terjadi. Ciletuh di selatan Sukabumi, Jawa Barat sebagai alternatif tujuan geowisata kawasan konservasi UNESCO Global Geopark telah mengalami penyesuaian tata alam karena pembangunan akses tranportasi roda empat. Kawasan ini menghadapi potensi masalah longsor. Tujuan dari penelitian ini adalah upaya mengurangi resiko terjadinya longsor melalui satu sistem informasi kawasan. Dalam mencapai tujuan, metodologi kualitatif yang digunakan adalah deskriptif analitis. Teknik pengumpulan data dengan melakukan tinjauan literatur, observasi dan wawancara mendalam. Hasil penelitian menunjukan bahwa sistem informasi berupa rambu-rambu agar berhati-hati saat melintas perlu dilengkapi dengan aplikasi multimedia. Melalui pendekatan desain komunikasi visual, info grafis sebagai materi edukasi penanggulangan bencana menjadi lebih mudah dimengerti bagi masyarakat. Kawasan Ciletuh yang sudah menjadi kawasan UNESCO Global
\end{abstract}


Geopark Network harus memiliki regulasi lengkap sebagai acuan dalam pengelolaan kawasan geowisata tangguh bencana.

Kata kunci: Ciletuh, edukasi, longsor, geowisata, multi media, rambu

\section{PENDAHULUAN}

Nusantara terbentuk akibat tertekannya kulit bumi pada bagian dasar samudra naik ke permukaan laut jutaan tahun lalu. Untuk membuktikan peristiwa tersebut dapat dilihat pada fosil-fosil binatang laut yang nampak pada dinding gunung batu mulai dari Sumatra, Jawa, hingga Papua. Akibat bumi berevolusi adalah bentang alam yang terbentuk menghasilkan keragaman pemandangan alam dimulai dari pemandangan di pegunungan hingga ke dataran rendah daerah pantai dan taman laut. Keragaman keindahan alam telah menjadi daya tarik masyarakat sebagai objek yang menarik untuk dikunjungi berulang kali.

Keindahan alam mulai terganggu ketika revolusi industri terjadi, imperiliasme dan sistem ekonomi kapitalis. Sejak tiga abad lalu alih fungsi lahan konservasi dan lahan pertanian berubah menjadi lahan perkebunan, lahan industri dan lahan pemukiman. Evolusi berujung pada terjadinya perubahan iklim global akibat ketimpangan akselerasi hasil penelitian sebagai dasar suatu regulasi tidak secepat pertumbuhan populasi manusia dengan segala upaya perekonomiannya.

Jakarta sebagai Ibukota negara Republik Indonesia menjadi kota tujuan masyarakat luar daerah untuk berurbanisasi. Saat ini penduduk asli Jakarta tersingkir ke tepi kota karena dominasi masyarakat urban. Persaingan ketat dan tekanan ekonomi menimbulkan kebutuhan rekreasi sebagai penyeimbang.

Secara geografis Jakarta berada pada dataran rendah sisi utara Pulau Jawa bagian barat. Pantai menjadi batas utara kota ini dengan demikian suhu di kota Jakarta berkisar $26^{\circ} \mathrm{C}$ di malam hari dan $35^{\circ} \mathrm{C}$ di siang hari. Hal ini menjadi latar belakang masyarakat Jakarta gemar berekreasi datang ke daerah dengan suhu udara sejuk. Kawasan peristirahatan Puncak Pass - Ciloto yang berada di Pegunungan Gede Pangrango sering menjadi tujuan rekreasi yang hanya menempuh dua jam perjalanan menggunakan kendaraan bermotor. Salah satu penelitian mengungkapkan antara tahun 1998 - 2018 sering terjadi longsor di daerah tersebut. Longsor yang dikategorikan bencana alam akibat kontur bukit yang curam, anomali debit hujan yang tinggi. Data lain menunjukan penggunaan lahan untuk membangun bangunan, drainase yang buruk dan peletakan material berat serta getaran di area yang seharusnya dibiarkan kosong juga menjadi pemicu terjadinya longsor parah pada 2018 hingga bangunan penginapan Puncak Pass ikut terseret longsor (Hayati, Niemeier and Sadarviana, 2020).

Jarak $130 \mathrm{~km}$ ke arah selatan dari Puncak Pass terdapat kawasan geowisata Ciletuh yang merupakan bagian dari Ciletuh Palabuhanratu UNESCO Global Geopark. Pada tahun 2017 kawasan ini mendapat perhatian dari Biofarma dengan melakukan pelatihan-pelatihan kepada masyarakat setempat dan membangun beberapa puskesmas. Gubernur Jawa Barat saat pemerintahan. Ahmad Heryawan melihat kawasan ini istimewa dan layak dijadikan tujuan geowisata. Maka bersama Mega Rosana Fatimah 
dari Fakultas Geologi Universitas Padjajaran, kawasan ini diusulkan menjadi geowisata kepada UNESCO. Usulan diterima karena mengacu pada tiga pilar menurut Global Geopark suatu kawasan konservasi yang memiliki keragaman geologi, keragaman hayati dan keragaman budaya layak menjadi anggota UNESCO Global Geopark. Demi kelancaran aksesibilitas ke Ciletuh, pemerintah Jawa Barat saat itu mengeluarkan dana hingga 800 miliar rupiah untuk membangun infrastruktur berupa jalan yang bisa dilalui oleh kendaraan bermotor sepanjang $33 \mathrm{~km}$ mulai dari Jalan Loji hingga desa Ciemas longsor (Mega Rosana Fatimah, 2020). Akibat pembuatan jalan ini timbul konsekuensi yang harus diperhitungkan di antaranya ancaman longsor akibat bukit yang ditembus oleh jalan, kemungkinan banyak homestay akan dibangun untuk menampung wisatawan, alih fungsi lahan konservasi menjadi lahan pemberdayaan bernilai ekonomis. Agar longsor di Ciloto tidak terjadi di Ciletuh perlu dilakukan beberapa program-program antisipasi untuk mengurangi risiko terjadinya bencana tersebut.

\section{HASIL DAN PEMBAHASAN}

\section{United Nation Education Science Culture Organization (UNESCO) - Earth Science dan United Nation on Disaster Risk Reduction (UNDRR)}

UNESCO adalah badan dunia yang fokus memperhatikan bidang edukasi, ilmu pengetahuan dan kebudayaan. Program Geopark berkaitan erat dengan ilmu tentang kebumian. UNESCO Global Geopark adalah progam jaringan geowisata global mengembangkan program yang memadukan suatu area geografis dengan situs dan bentang alam geologi, secara internasional dikelola dengan konsep konservasi, edukasi, dan pengembangan yang berkelanjutan secara holistik dengan mengadopsi pendekatan dari lini bawah ke atas. Dengan cara menggabungkan konservasi alam bersamaan dengan pengembangan berkelanjutan yang melibatkan masyarakat lokal. Hingga Juli 2020 anggota UNESCO Global Geopark telah tersebar sebanyak 161 titik lokasi di 44 negara di dunia.

Perubahan iklim pemicu berbagai bencana alam di dunia telah menjadi perhatian badan dunia. Sejak 1989 hingga saat ini setiap tanggal 13 Oktober diperingati sebagai International Day of Disaster Risk Reduction. UNDRR organisasi yang menangani hal ini, menurunkannya melalui program Sendai Framework. Satu dari beberapa program yang menjadi agenda kerja adalah negara-negara di dunia mendapat paparan program edukasi pengurangan resiko bencana. Dalam kurun waktu 2015 hingga 2030 ditargetkan masyarakat dunia sudah lebih siap mengahadapi bencana karena sudah dibekali keterampilan penanggulangan melalui pelatihan-pelatihan secara intensif untuk beberapa jenis bencana. Dengan demikian angka kematian dan kerugian yang mungkin timbul akibat bencana hingga tahun 2030 bisa ditekan.

Rentang waktu program Sendai Framework telah memberi inspirasi U-Inspire Alliance sebagai organisasi sains muda di bawah bimbingan UNESCO. Seperti dikutip dari situs resmi mereka bahwa aliansi ini adalah aliansi pemuda dan profesional muda Asia Pasifik di bidang sains, teknik, teknologi, dan inovasi untuk pengurangan risiko bencana dan perubahan iklim, yang dibentuk saat Deklarasi Jakarta 20 September 2019. 
U-Inspire Alliance memiliki visi membangun koordinasi dan kolaborasi yang kuat dalam pemberdayaan pemuda dan profesional muda dalam sains, teknik, teknologi, dan inovasi dalam pengurangan risiko bencana di tingkat global. Tujuannya untuk menjalin hubungan yang kuat antara pemuda dan profesional muda untuk bekerja dan menjadi sukarelawan dalam pengurangan risiko bencana di kawasan Asia Pasifik, memungkinkan berbagi informasi, pengumpulan informasi, dan memungkinkan jejaring regional dan kolaborasi dengan berbagai lembaga nasional dan lokal.

Menurut informasi Nuraini Rahma Hanifa sebagai Sekertasris Jendral U-I Alliance ranting Jakarta mereka yang berusia di antara 15 tahun hingga 30 tahun dan profesional hingga 40 tahun bisa bergabung di wadah ini. Contoh kegiatan ilmuwanilmuwan muda ini adalah mendatangi Sekolah Dasar untuk mendemonstrasikan bagaimana terjadi likuifaksi, yaitu fenomena pencairan tanah yang terjadi ketika kondisi tanah yang jenuh kehilangan kekuatannya dan kekakuannya akibat adanya tegangan. Demonstrasi dilakukan dengan memperlihatkan kotak pasir dan miniatur rumah tertata di permukaan pasir. Kotak tersebut diberi guncangan sehingga miniatur rumah tenggelam ke dalam pasir. Desainer Komunikasi Visual ikut berpartisipasi dalam edukasi ini dengan mengembangkan aplikasi multi media berisi infografis persiapan apa saja yang harus dilakukan jika terjadi bencana.

\section{Geopark Nasional dan UNESCO Global Geopark di Indonesia}

Taman-taman Nasional dan Cagar Alam yang berada di Indonesia adalah awal dari Geopark-geopark Nasional yang kemudian naik peringkatnya menjadi UNESCO Global Geopark setelah melalui proses penilaian dari tim penilai UNESCO Global Geopark Paris. Hingga saat ini di Indonesia tercatat 14 Geopark Nasional dan 5 UNESCO Global Geopark (Gambar 1). Geopark-geopark tersebut berkumpul dalam satu wadah yang disebut jaringan Geopark Indonesia agar pergerakan mereka terarah dalam hal pengembangan, pengoperasian dan pengelolaan serta pengawasan.

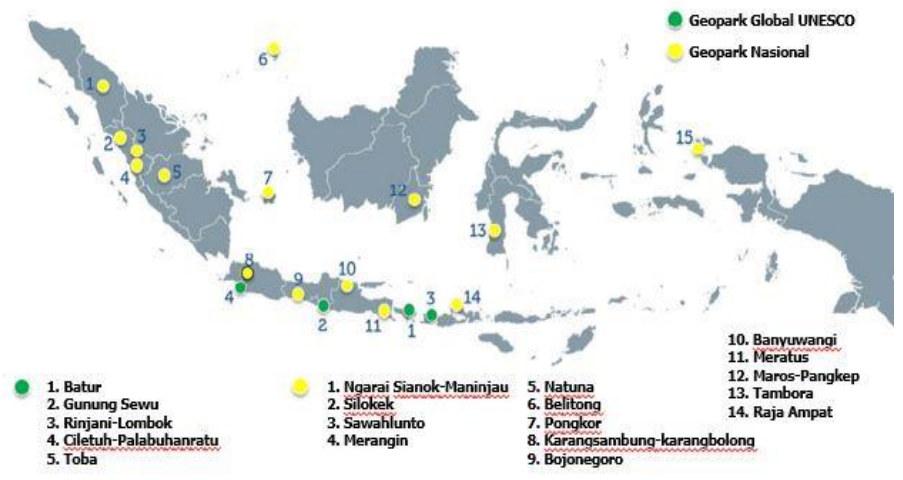

Gambar 1. Peta persebaran UGGNs dan National Geoparks di Indonesia

Sumber: Materi Presentasi Dr. Hanang Samodra Webinar Pengembangan Geopark di Indonesia Kementrian Koordinasi Bidang Kemaritiman dan Investasi Kamis, 18 Juni 2020.

Secara geologi ada tiga lempeng tektonik yang wajib diketahui berkaitan dengan posisi wilayah Indonesia yaitu terletak di antara Lempeng Eurasia, Lempeng Pasifik, 
dan Lempeng Hindia-Australia. Kondisi ini menyebabkan Indonesia rentan terhadap gempa bumi, tsunami, erupsi gunungapi, banjir, tanah longsor, puting beliung, kekeringan, serta kebakaran hutan dan lahan.

Sebagai upaya pencegahan dan penanggulangan maka diterbitkan Undangundang Nomor 24 Tahun 2007 menyebutkan Pemerintah Pusat dan Pemerintah Daerah menjadi penanggung jawab penyelenggaraan penanggulangan bencana. Oleh karena itu, dibentuklah Badan Nasional Penanggulangan Bencana (BNPB) dengan tanggung jawab menyelenggaraan penanggulangan bencana di tingkat nasional dengan didukung oleh Kementerian dan Lembaga terkait, seperti Kementerian Pekerjaan Umum dan Perumahan Rakyat, Kementerian Kesehatan, Kementerian Sosial, Kementerian Dalam Negeri, TNI, Polri, Badan Pencarian dan Pertolongan (Basarnas), Badan Meteorologi, Klimatologi dan Geofisika (BMKG), Pusat Vulkanologi dan Mitigasi Bencana Geologi (PVMBG), dan lembaga terkait lain. BNPB diturunkan ke tingkat provinsi menjadi Badan Penanggulangan Bencana Daerah (BPBD).

\section{Ciletuh}

Menyadur keterangan dari Mega Fatimah Rosana, kata Ciletuh memiliki arti air yang keruh mengingat secara geografis kawasan ini merupakan pertemuan dari beberapa anak sungai sebelum sampai ke laut. Sungai-sungai tersebut membawa sedimen tanah merah sehingga dapat dilihat dari beberapa air terjun dari sungai-sungai sekitar pada musim-musim tertentu yang airnya berwarna kecoklatan. Posisi Ciletuh berada di Selatan Kota Sukabumi, Jawa Barat. Geowisatawan datang akan melewati Jembatan Kuning melintas ruas Sungai Cimandiri. Jembatan ini merupakan peninggalan budaya karya asrsitek Inggris pada zaman penjajahan Belanda. Puncak Darma sebagai titik memasuki kawasan Ciletuh ditempuh melalui Jalan Loji. Pada ketinggian ini geowisatawan dapat melihat teluk Ciletuh yang membentuk setengah lingkaran.

Menuruni dataran tinggi Puncak Darma terdapat destinasi air terjun Curug Cimarinjung, air terjun dengan aliran air yang deras dan keruh karena membawa sedimentasi. Titik destinasi wisata selanjutnya adalah Pantai Palangpang terdapat landmark bertuliskan "Geopark Ciletuh" tempat wisatawan berswafoto dibuat sejak kawasan ini belum mendapat predikat UNESCO Global Geopark. Jenis batuan paling tua bisa ditemukan di Ciletuh dikenal dalam bahasa geologi sebagai batuan Melange yaitu batuan campur yang pembentukannya berasal dari zona subduksi. Sebagian peneliti menyebutnya ini bukti tumbukan yaitu bebatuan yang masuk ke jalur tumbukan atau zona palung kemudian terangkat ke daratan. Batuan tua lainnya terdapat di Gunung Badak yang merupakan kawasan cagar alam Cibanten, masyarakat setempat menyebutnya sebagai Pulau Kunti. Pada satu sisi Gunung Badak terdapat aliran lava bantal. Sebaran batuan peridotit yang tertutup rumput dijumpai pada dinding Gunung Aseupan. Komposisi batuan sedimen, batu pasir dan komposisi batuan vulkanik terdapat di Pulau Mandra dan Pulau Kunti. Akibat proses patahan bumi, di kawasan ini banyak dijumpai air terjun atau curug. Beberapa yang dikenal wisatawan antara lain adalah Curug Sodong, yaitu curug yang terdiri dari empat air terjun, dan berdekatan dengan 
tempat ini terdapat pula Curug Cikanteh. Air terjun di kawasan ini yang paling menjadi incaran untuk dikunjungi adalah adalah Curug Awang, curug yang berada di aliran sungai Ciletuh dengan pelapisan batuan vertikal yang sejajar. Pada sisi kiri dan kanan dari Curug Awang, terdapat bentangan sawah. Pada saat air di air terjun ini surut geowisatawan bisa menapaki batu-batu hingga dapat melihat jurang di bawahnya. Di aliran sungai yang sama lebih ke bawah terdapat Curug Tengah yang ditepiannya terdapat saluran irigasi (Gambar 2).

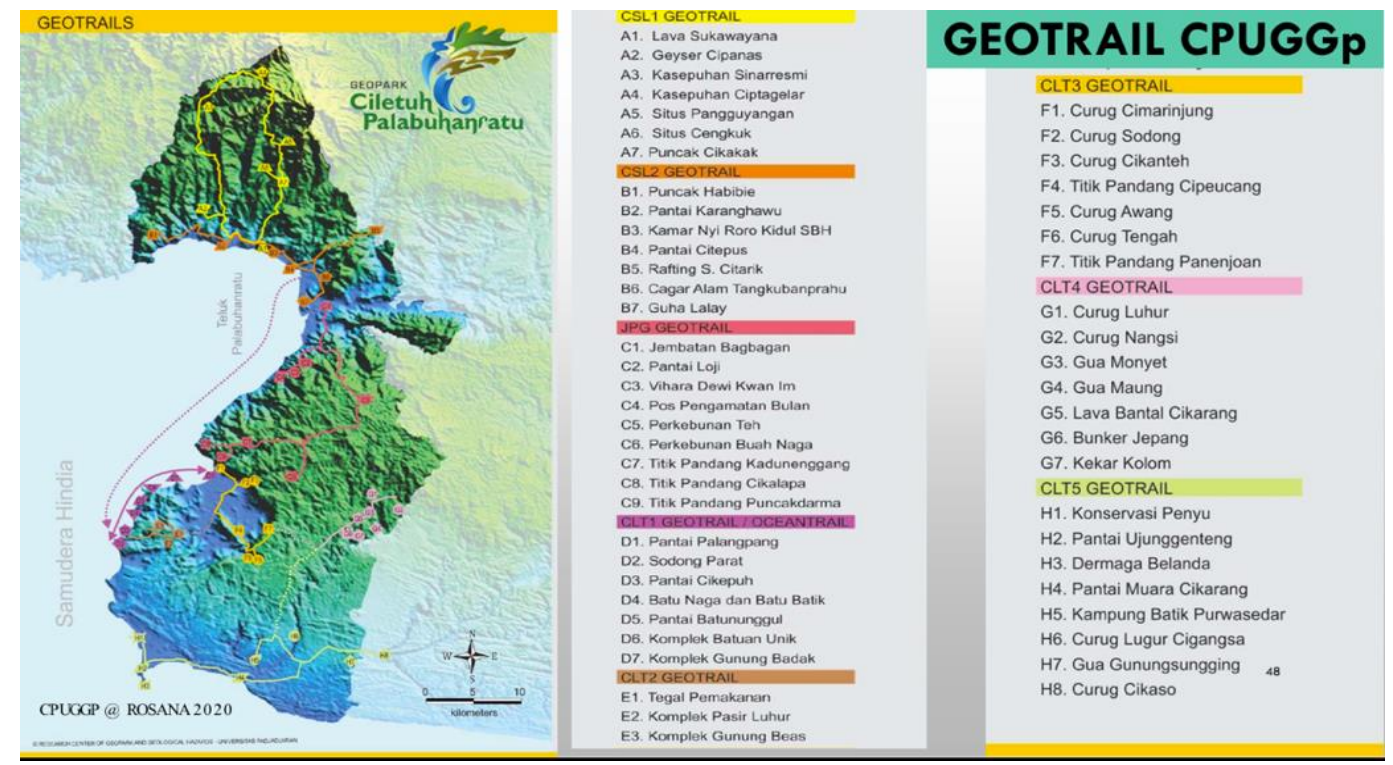

Gambar 2. Peta Geopark Ciletuh Palabuhanratu

Sumber: Prof. Mega Fatimah Rosana, Virtual Geotour - Ciletuh-Palabuhanratu UGG, 2020

Pada bentang alam dari ketinggian lembah mega amphitheater ke arah dinding Panenjoan terdapat triangular facet yaitu bentuk segitiga pada dinding sebagai bukti bahwa dulu kala adalah sesar sehingga membentuk satu lembah raksasa menjadi cekungan (Gambar 3). Beberapa melihatnya sebagai bentuk setengah lingkaran atau seperti bentuk tapal kuda dengan diameter sekitar $15 \mathrm{~km}$ yang sekarang dikenal sebagai amphitheater Ciletuh.

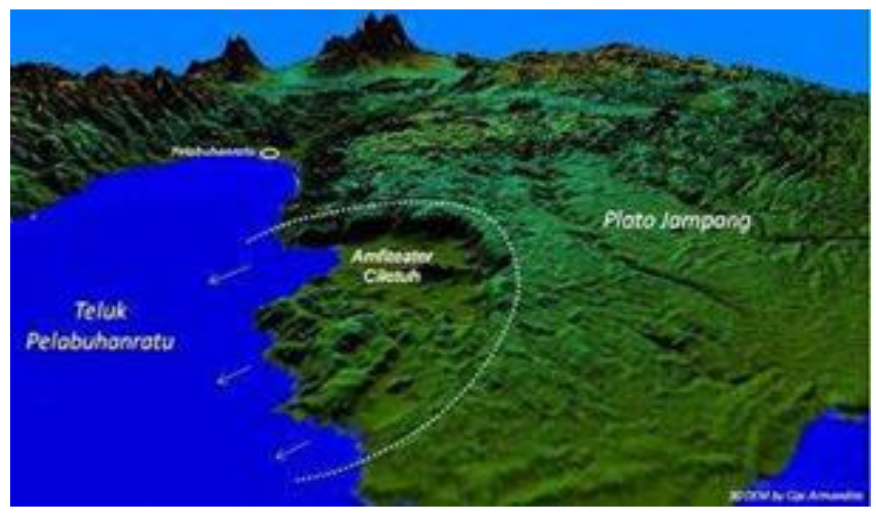

Gambar 3. Mega amphitheater Ciletuh

Sumber: Prof. Mega Fatimah Rosana, Virtual Geotour - Ciletuh-Palabuhanratu UGG, 2020. 
Kegiatan pengembangan sumber daya alam dilakukan oleh masyarakat setempat dalam wadah Paguyuban Alam Pakidulan Sukabumi (PAPSI) di Museum Konservasi PAPSI. Di dalam museum ini, banyak terpajang bebatuan yang dikelola oleh masyarakat. Alternatif kegiatan rekreasi pilihan wisatawan adalah rekreasi air di Leuwi Kenit River Tubing. Perjalanan yang dimulai dari dataran tinggi dan selesai di pantai Pangumbahan di Ciletuh. Pantai yang luas dengan pasir putih yang halus termasuk kawasan konservasi khusus untuk penyu hijau dikelola oleh Dinas Kelautan dan Perikanan Provinsi Jawa Barat. Berdampingan dengan kawasan suaka margasatwa tertutup bagi masyarakat umum berhadapan dengan Pantai Ombak Tujuh yang disukai peselancar profesional. Pengelola di kawasan ini melakukan seremonial melepas tukik atau anak penyu yang baru menetas ke laut selatan saat matahari terbenam.

\section{Keilmuan Rambu dan Sistem Penanda}

Pada setiap bentuk bangunan atau kawasan dipastikan memerlukan paket rambu sebagai sistem penanda menujukan arah. Perencana perambuan ini awalnya adalah perencana komunikasi visual dengan keminatan khusus untuk mendapatkan sudut pandang berbeda dari disiplin ilmu merancang lainnya. Karya rambu dari perencana komunikasi tersebut dapat ditemui pada gedung, bangunan, kawasan yang dikembangkan oleh pihak swasta maupun instansi pemerintah atas fasilitas publik yang mereka kelola. Sebagai contoh pusat perbelanjaan, area komersial, gedung perkantoran, hotel, apartemen, kawasan perumahan, sarana olah raga, sarana rekreasi, dan pusatpusat pendidikan. Dalam pembahasan ini terbuka kemungkinan untuk membangun satu perambuan atau sistem penanda yang terpadu untuk seluruh kawasan Ciletuh Palabuhan Ratu UNESCO Global Geopark.
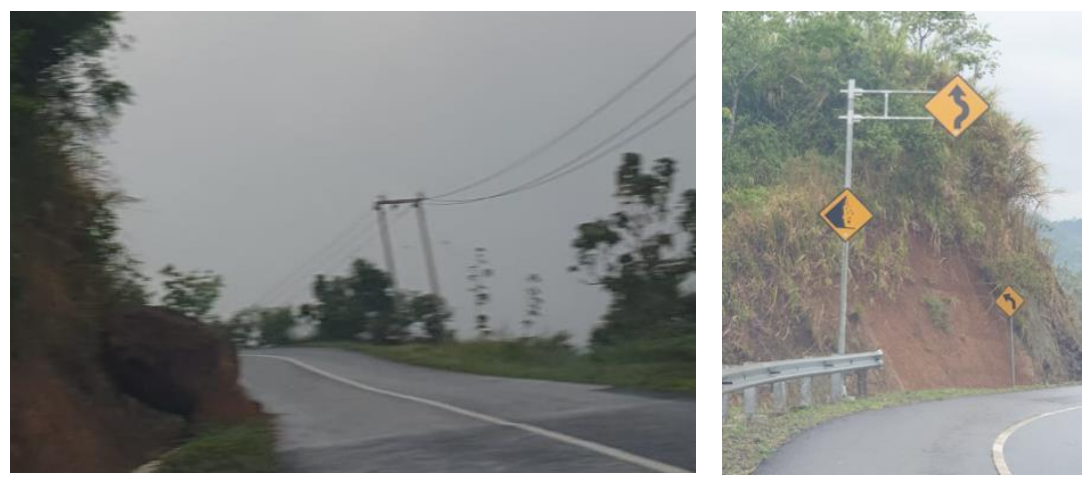

Gambar 4. Sisa longsor dan rambu pada ruas Jl. Loji - Ciemas Sumber: Dokumentasi Pribadi - 15 Oktober 2020.

Rujukan literatur kata rambu atau sistem penanda atau signage sering hadir bersama dengan padanannya menjadi signage and way finding. Bisa dijumpai pula dengan sebutan sign system. Istilah tersebut adalah sebagai bagian dari induk disiplin ilmu Environmental Graphic Design (EGD) yang artinya komunikasi grafis atas suatu informasi yang dibuat menyatu dengan lingkungan yang ada (Calori dan VandenEynden, 2015). Signage and wayfinding juga sering diungkapkan sebagai suatu program 
tanda terpadu yang secara informal dan tervisualisasi menyatukan satu situs dengan kumpulan situs terkait. Pernyataan tersebut kongruen dengan pengalaman penulis sebagai pelaku perencana sistem penanda lebih dari satu dekade berkontribusi pada industri properti. Hal ini adalah pengalaman di lapangan dan tidak didapatkan pada jalur akademis. Posisi desainer komunikasi visual terhadap displin ilmu lain dijelaskan seperti pada (Tabel 1) berikut.

\begin{tabular}{|l|l|c|c|l|l|}
$\begin{array}{l}\text { Kota/ } \\
\text { Desain Urban }\end{array}$ & $\begin{array}{l}\text { Arsitektur } \\
\text { Lansekap }\end{array}$ & Arsitektur & Desain Interior & $\begin{array}{l}\text { Produk } \\
\text { Industri }\end{array}$ & Desain Grafis \\
\hline $\begin{array}{l}\text { Kota, daerah, } \\
\text { kampus }\end{array}$ & $\begin{array}{l}\text { Ruang terbuka } \\
\text { terencana, } \\
\text { taman }\end{array}$ & Gedung & Ruang Interior & $\begin{array}{l}\text { Objek kerja dan } \\
\text { keseharian }\end{array}$ & $\begin{array}{l}\text { Objek yang } \\
\text { dikomunikasikan }\end{array}$ \\
Makro & $>$ Mikro
\end{tabular}

Tabel 1. Posisi desain grafis terhadap disiplin ilmu merencana lain pada perancangan Environmental Graphic Design \& Panel informasi.

Sumber: Signage and Wayfinding Design, Calori and Vanden-Eynden, 2015

\section{Society 5.0}

Sejak revolusi industri lahir di abad 17 siklus peradaban-peradaban manusia menjadi singkat. Di era 1990 ketika teknik teknologi informasi dan komputer berkembang menjadi teknologi digital siklus semakin singkat, semakin cepat berputar dan berubah arah. Pada mulanya teknologi dikembangkan untuk kemudahan kehidupan manusia. Di saat ini kondisi berbalik arah, teknologi menempatkan manusia pada posisi tidak menentu. Suatu penemuan dianggap menjawab satu kebutuhan seketika usang dengan penemuan lain yang mengakomodasi lebih dari yang dibutuhkan, buah dari artificial intelligence kembangan dari teknologi digital. Di beberapa negara maju posisi artificial intelligence telah mengganti posisi manusia sehingga kurva populasi usia dini hingga remaja lebih kecil daripada usia produktif dan lansia. Kenyataan yang memprihatinkan karena menjadi ancaman di suatu masa tekonologi hanya melahirkan robot-robot lebih banyak dibandingkan regenerasi populasi manusia.

Negara Jepang kemudian meredefinisi ulang paradigma tersebut di atas menjadi Society 5.0 pada April 2016 menyadur jurnal yang disusun oleh Kayona Fukuda. Didefinisikan sebagai masyarakat baru di tahap kelima melanjutkan empat tahap sebelumnya yaitu masyarakat berburu, masyarakat agraris, masyarakat industri dan masyarakat informasi. Tujuannya adalah untuk menciptakan masyarakat yang berpusat pada manusia di mana produk dan layanan akan difasilitasi sebagai pemenuhan berbagai potensi kebutuhan serta mengurangi kesenjangan ekonomi dan sosial. Manusia bisa menjalani kehidupan yang nyaman dan penuh semangat (Fukuda, 2020).

\section{Prediksi dalam Otak}

Otak manusia merupakan miniatur alam semesta lengkap dengan elemen-elemen yang ada serta kegiatan-kegiatan yang ada di dalamnya. Sebagai contoh mikro elemen bangunan yang dibangun di atas permukaan bumi untuk memenuhi kebutuhan manusia. 
Dalam pemanfaatannya, agar bangunan itu menjadi efektif diperlukan rambu sistem penanda sehingga pengguna bangunan tersebut cepat dan benar dalam mencapai tujuan yang ada di dalamnya. Demikian halnya dengan otak manusia yang terdiri dari blokblok bangunan dengan fungsi yang berbeda-beda. Dalam pembentukan memori terdapat transaksi data hasil dari persepsi indrawi. Data-data tersebut akan disimpan dalam blok otak tertentu agar proses penyimpanan sampai pada blok yang tepat. Organ otak bernama hippocampus bertugas untuk memberi pengarahan dan bertugas memanggilnya kembali jika suatu memori diperlukan. Demikian menyadur dari Pallasma dalam buku yang ditulisnya (Pallasmaa, Mallgrave and Arbib, 2013).

Otak berkinerja sepanjang hidup manusia dengan memberi dan menerima stimuli yang ditangkap dari organ tubuh lainnya untuk dimaknai. Pada beberapa proses diketahui otak memiliki serangkaian sel dengan pembawaan menduga-duga apa yang akan terjadi kemudian dengan kata lain suka memprediksi setelah merespon tanda-tanda visual yang diterimanya (Pulvermüller dan Grisoni, 2020).

\section{SIMPULAN}

United Nation sebagai badan dunia melalui UNDRR dan UNESCO secara konsisten meluncurkan hasil-hasil temuan melalui ilmu pengetahuan dan teknologi untk pengurangan resiko bencana. Rambu yang mengkomunikasikan akan bahaya bencana mendapat rekomendasi untuk tampil dalam suatu lingkungan Geopark seperti dikatakan Ross Dowling penggiat Global Geopark Network berkebangsaan Australia (Brown, 2019). Program UNESCO Global Geopark agar masyarakat lebih dekat dan menghormati alam serta masyarakat yang telah menjaga warisan alam dapat berjalan parelel dengan gerakan Society 5.0 yang terorientasi pada manusia.

Pada skala nasional BMKG, BNPB dan BPBD untuk sebaran ke berbagai pelosok melakukan hal yang sama. Secara kelokalan penggalian-penggalian kearifan lokal agar bijak pada alam dimunculkan kembali. Seperti pada diskusi K3 untuk lingkungan geopark disampaikan oleh Budi Martono - Ketua Jaringan Geopark Indonesia mengenai early warning system di kawasan Gunung Sewu UNESCO Global Geopark yang dikelolanya. Rambu-rambu jalur evakuasi, program BNPB agar desadesa di sana menjadi desa tangguh bencana sehingga jika terjadi bencana warga sudah diajarkan ke arah mana geowisatawan harus menyelamatkan diri. Apa yang telah dilakukan ini adalah sebagai pilot project tidak hanya untuk bencana alam tapi juga untuk penanggulangan pandemi. Lewat program wijik resik yang terinspirasi dari kearifan lokal Gunung Kidul. Proses duplikasi telah terjadi di Ciletuh, saat ini sudah ada 2 desa yang masuk pada kategori desa tangguh bencana yaitu desa Ciwaru dan Mandrajaya yang terletak dihadapan teluk Ciletuh. Lebih mengerucut BPBD Jawa Barat sudah meluncurkan program keluarga tangguh bencana. Merespon frekuensi banjir bandang di Garut dan tanah longsor di Sukabumi yang sering terjadi. 


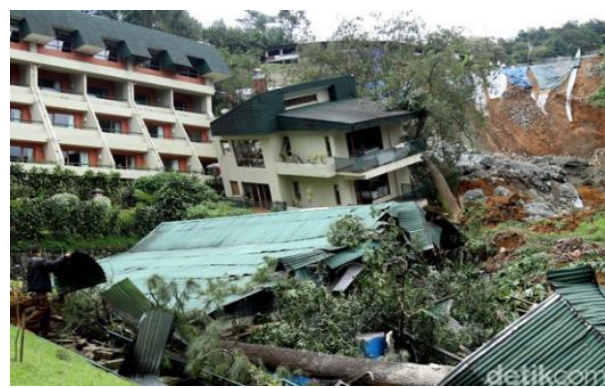

Gambar 5. Bangunan yang tertimbun longsor di kawasan Puncak Pas, Cianjur, Jawa Barat (Sumber: detik.com - 2018).

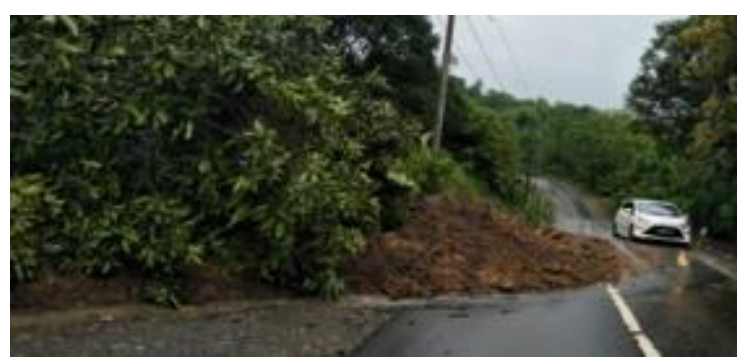

Gambar 6. Longsor menutupi akses jalan menuju Geopark Ciletuh Palabuhanratu (Sumber: Website BPBD Sukabumi, 2018).

BPBD fokus pada antisipasi bencana longsor di kawasan Ciletuh Palabuhan Ratu UNESCO Global Geoparks. Bencana longsor dipicu oleh faktor manusia daripada alam akibat alih fungsi alam dari lahan konservasi ke lahan berdaya guna dan bernilai ekonomis. Multi disiplin ilmu diadopsi untuk edukasi. Desain komunikasi visual mengayakan materi edukasi melalui konten infografis sehingga desa-desa yang sudah berpredikat Desa Tangguh Bencana bisa menjadi konten promosi kawasan geowisata ini. Ilmu Teknologi Informasi berperan memberi teknik sosialisasi atas konten pada infografis. Ilmu Teknik Sipil memberi edukasi membangun fasilitas penginapan serta infrastruktur menyesuaikan kontur lahan. Ilmu Arsitektur memberi edukasi dalam membangun fasilitas yang efektif dalam fungsi dan estetis dalam tampilan yang kuat dengan identitas lokal. Ilmu arsitektur lanskap berperan mengedukasi jenis-jenis vegetasi yang mampu menahan beban serta resapan air.

Informasi bahwa homestay-homestay dikelola keluarga tangguh bencana yang dipublikasikan melalui sistem informasi aplikasi multimedia pada gawai sehingga menimbulkan rasa aman dari geowisatawan sejak saat sebelum berkunjung.

\section{DAFTAR PUSTAKA}

Brown, E. (2019) 'Handbook of Geotourism Book Review', in Proceedings of the Geologists' Association. Worcester: Elsevier.

Calori, C. and Vanden-Eynden, D. (2015) Signage and Wayfinding Design. 2nd edn. New Jersey: John Wiley \& Sons.

Fukuda, K. (2020) 'Science, technology and innovation ecosystem transformation toward society 5.0', International Journal of Production Economics, 220(April 2019), p. 107460. doi: 10.1016/j.ijpe.2019.07.033.

Hayati, N., Niemeier, W. and Sadarviana, V. (2020) 'Ground deformation in the ciloto landslides area revealed by multi-temporal InSAR', Geosciences (Switzerland), 10(5), pp. 1-16. doi: 10.3390/geosciences10050156.

Pallasmaa, J., Mallgrave, H. F. and Arbib, M. (2013) Architecture \& Neuroscience: a Tapio Wirkkala-Rut Bryk Design Reader, Architecture \& Neuroscience. Edited by P. Tidwell. Espoo: Tapio Wirkkala - Rut Bryk Foundation. 
Pulvermüller, F. and Grisoni, L. (2020) 'Semantic Prediction in Brain and Mind', Trends in Cognitive Sciences, 24(10), pp. 781-784. doi: 10.1016/j.tics.2020.07.002.

\section{REFERENSI DIGITAL}

BPBD Kabupaten Sukabumi. (2020). BNPB dan Akademisi Perkuat Ketangguhan Keluarga Dalam Menghadapi Bencana di Tengah Pandemi COVID-19. Available at: https://bpbd.sukabumikota.go.id/bnpb-dan-akademisi-perkuatketangguhan-keluarga-dalam-menghadapi-bencana-di-tengah-pandemi-covid19/ (Accessed: 15 November 2020)

BPBD Kabupaten Sukabumi. (2018). Hujan Deras, Longsor Terjang Akses Jalan Geopark Ciletuh Palabuhanratu. Available at: https://bpbd.sukabumikab.go.id/hujan-deras-longsor-terjang-akses-jalangeopark-ciletuh-palabuhanratu/ (Accessed: 15 November 2020)

FGMI TV. Virtual Geotour - Ciletuh-Palabuhanratu UGGp Available at: https://youtu.be/ibUYkhjWnJ4 (Accessed: 26 April 2020).

Martono, B. (2020). Webinar Menilik K3 di Dunia Keteknikan Serta Geotourism di Kawasan Gunung Sewu UNESCO Global Geopark, Fakultas Teknik Universitas Lampung. Available at: https://www.instagram.com/p/CHrEkHRIVAj/?utm_source=ig_web_copy_link (Accessed: 15 November 2020)

Rifkianto Nugroho. (2018). Begini Bentuk Bangunan yang Tertimbun Longsor di Puncak. Available at: https://news.detik.com/foto-news/d-3943321/beginibentuk-bangunan-yang-tertimbun-longsor-di-puncak (Accessed: 15 November 2020)

Rosanah, M, F. (2020). Webinar Virtual Tour Ciletuh Palabuhan Ratu UNESCO Global Geopark. Available at. https://youtu.be/ibUYkhjWnJ4 (Accessed: 26 April 2020)

Samodra, H. (2020). Webinar Pengembangan Geopark di Indonesia Kementrian Koordinasi Bidang Kemaritiman dan Investasi. Available at. https://www.youtube.com/watch?v=hp-SUFZycYk (Accessed: 18 Juni 2020)

U-INSPIRE Alliance, Asia Pacific Youth and Young Professionals Alliance in Science, Engineering, Technology, and Innovation for Disaster Risk Reduction and Climate Change. Available at: http://www.uinspirealliance.org/. (Accessed: 15 November 2020

United Nations Educational, Scientific and Cultural Organization Jakarta. \#1:, DRR Talk Science, Engineering, Technology and Innovation into Reduction, Action in Disaster Risk. Available at: https://web.facebook.com/602642980127883/videos/661337534557442/ (Accessed: 12 November 2020).

United Nation Office for Disaster Risk Reduction. https://www.undrr.org/publications. (Accessed: 14 November 2020). 